\title{
Measuring Public Transport Accessibility for Elderly
}

\author{
Kaniz Fatima ${ }^{1}$, Sara Moridpour ${ }^{2}$ \\ ${ }^{1}$ PHD Student, RMIT University, Department of Engineering, Melbourne, Australia \\ ${ }^{2}$ Senior Lecturer, RMIT University, Department of Engineering, Melbourne, Australia
}

\begin{abstract}
The growth acceleration in the older population has been observed in many countries which creates a significant challenge to transportation. Public transport is an essential component of most people's lives. This specific group of population growth will require special attention to accessibility and mobility issues in combination with the transport system which undoubtedly can play a key role to support ageing. Good health, quality of life and independence are fundamental values for the life as well as mobility. For people such as senior citizens, public transport needs to be accessible and affordable in order to provide them with the opportunity to fulfil their medical, shopping and recreational needs. Providing access to transport for people with age $65 \&$ over is not a marginal problem and it is expected to grow in the future. The most important concern in accessibility is the relatively short distance and high frequency movements from a permanent home. This study will identify the travel pattern \& mode for elderly commuters in greater Melbourne, Australia. The study will also suggest strategies to improve the use of public transport system to promote ageing in place.
\end{abstract}

\section{Introduction}

Over the next few decades with the ageing of the baby boomer generation (those born between 1946 and 1964) combined with the increase in longevity and declining birth rates will produce a new aged group population all over the world [1]. By the middle of the next century roughly one in three citizens of the world's industrial nations will be over 65 [2]. At present people aged 65 years and over make up 13 per cent of Australia's population. By 2051, this proportion is projected to increase to more than 25 per cent, or more than onequarter of the population. The over 85 age group is expected to 8.6 per cent by 2051 [3]. Figure 1 represents the aged population growth in a percentage all over the world. Good health, quality of life and independence are fundamental values for the life as well as mobility.

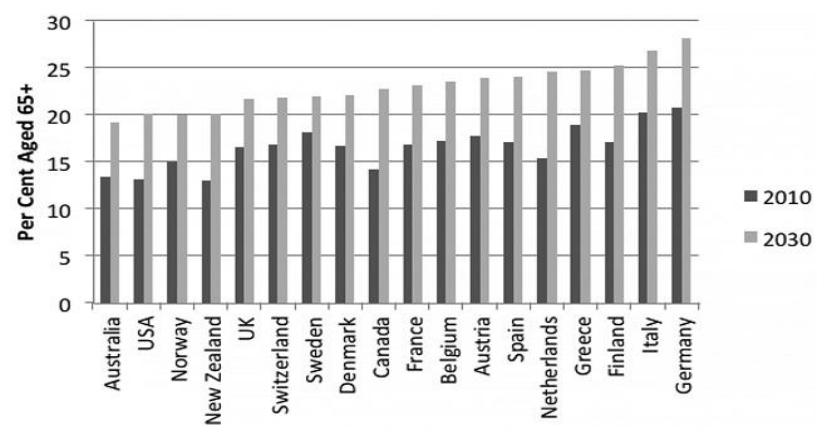

Figure 1. Aged people growth (\%) in developed countries. (Source: United Nations, Department of Economic and Social Affairs)
The aim of this study is to identify Melbourne elderly travel pattern \& public transportation accessibility. The study also proposes strategies to increase the quality of public transport usage among elderly commuters.

\section{Literature review}

The travel need of the older population may be even greater than the younger population since they more time for non-home activities and need more social services and health care [4]. Therefore, it is imperative to develop policies to help the increasing number of older people maintain necessary mobility in an aging society [5]. Mobility and accessibility are two important term for transport system. In brief, mobility concerns the way the individual moves, the conditions and infrastructure that are presented to him, the quality of transport, in relation to the ease with which the movement is made. Meanwhile accessibility is the objective of displacement itself and concerns issues related to distance, time and cost to reach a certain destination from a particular origin. The transport system cannot be claimed well enough without having mobility \& accessibility for all age group of people. Travel by private transport is most comfortable \& flexible way. Public transport accessibility policy should be a new better alternative to avoid dependency on private transport. [6] pointed out proper accessibility for elderly is not only important to older people themselves but also to those with who senior interact (especially 
where these others rely on tasks such as child care and voluntary work undertaken by senior citizens).

\subsection{Elderly travel pattern \& public transport accessibility}

\subsubsection{Ageing in Place}

Many of senior people have chosen to remain living in their homes rather than in retirement villages or other forms of aged care accommodation that may have better access to services. This living style is known as "Aging in place". As a result they are adding numbers to the existing suburb population. In Australia it is now much more difficult to ensure their accessibility to both public \& private transport facilities [7]. For older people who are no longer part of the main workforce, transportation is a way to maintain social bonds. As a result, the transport is strongly linked to independence, freedom of movement, choice, social activity and community involvement [8]. Most of the traditional transportation \& environmental planning ignores the older people contribution [9]. The focus of this paper is to improve public transport accessibility expectations of seniors.

\subsubsection{Elderly Trip Pattern}

Mostly older people travel to meet their daily needs. Their trip-making primarily occurs during a mid-day peak and daylight hours. [10] studying New Zealanders showed that compared to younger adults (25-59), those aged 65 and over: do fewer trip per day; make shorter trips; travel fewer vehicle kilometres per day or year; make most trips with the purpose of social/recreational/personal business; have more 'at home' days than the general population; make a higher proportion of their trips as a passenger in a vehicle and fewer as a driver; make most of their trips between 9:30 a.m. and 3 p.m. [11].

Most common place to travel for the senior population group is shopping, health care centre \& retirement recreation [12]. Some of the senior people are self-employed. It may also include some trips being made to undertake voluntary work, particularly formal volunteering [13]. Very few education trips are made by older people. A part of older population group is involved in 'Education escort' means taking children to school. Senior traveller also travel to visit retail services - banks, post office and chemists. One reason older people make fewer trips than younger people are because some of them find travelling through public transport is difficult. It can be seen that mobility difficulties increase with age, with only $4 \%$ of younger people having such difficulties, which increases to $17 \%$ for those aged $60-69$ and to $39 \%$ for those aged 70 and over [6].

Using VISTA (Victorian Integrated Survey of Travel and Activity) 2012 travel pattern has been analysed by statistical software SPSS. Figure 2 represents the travel pattern for elderly commuters. Figure 3 represents elderly trip time using VISTA data 2012.

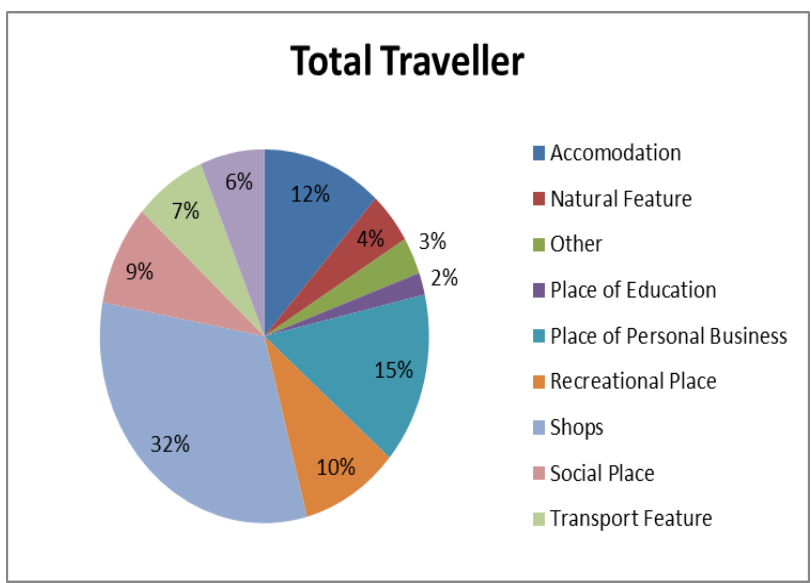

Figure 2.Travel pattern of aged people (VISTA 2012).

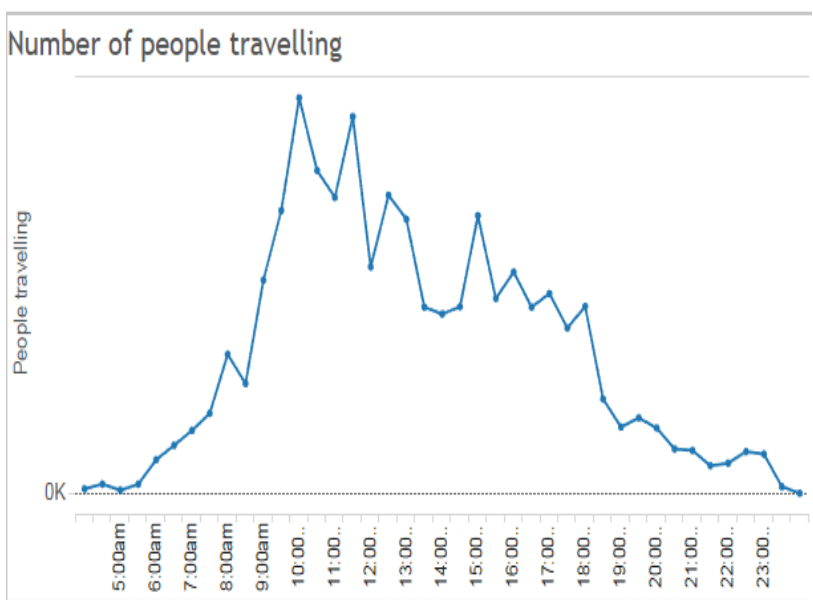

Figure 3.Preferred travel time for elderly (VISTA 2012).

\subsubsection{Attitudes to public transport}

A satisfactory journey using public transport will typically involve an acceptable walk to the bus stop along well maintained and well lit footways; a short, sheltered and secure wait for a service which arrives reliably, as expected from a readable timetable; a safe and comfortable journey which takes the traveller to a point for disembarking conveniently near to the final destination and a timely return service [14]. Considering public transport as main moving source group of elderly find it not easy. They mainly faced three difficulties as: 1) Facility and vehicle design. 2) Operation. 3) Cost [15].

In addition, within the accessibility problems there are several detail features that faced as obstacles for the elderly. Bad quality of the surfaces, the inaccessible approach of the communal toilets and the absence of railing in the ramp streets [13] are some of the examples. Some countries improved the design of steps, gaps, barriers and difficult changes in level which make accessibility easier for individuals in wheelchairs, the ambulant disabled and the elderly. Table 1 represents the summary of mode of transport choice for aged commuters in Melbourne. The table shows that elderly from Melbourne are more comfortable using private vehicle over public/active transport. 
Table 1. Elderly mode choice in Melbourne (VISTA 2012 [16]).

\begin{tabular}{|c|c|c|}
\hline $\begin{array}{c}\text { Transport } \\
\text { System }\end{array}$ & $\begin{array}{c}\text { Transport } \\
\text { Mode }\end{array}$ & $\begin{array}{c}\text { Commuter } \\
\text { (\%) }\end{array}$ \\
\hline \multirow{3}{*}{ Public Transport } & Bus & 1.5 \\
\cline { 2 - 3 } & Tram & 2.5 \\
\cline { 2 - 3 } & Train & 8.5 \\
\hline Active Transport & Walking & 2.7 \\
\hline \multirow{2}{*}{ Private Vehicle } & Vehicle Driver & 79 \\
\cline { 2 - 3 } & $\begin{array}{c}\text { Vehicle } \\
\text { Passenger }\end{array}$ & 4 \\
\hline \multirow{2}{*}{ Other } & Other & 1.8 \\
\hline
\end{tabular}

Majority of aged people stopped driving because of poor health condition. For health reason they step down from using public transport services as an option even if it is available. For example, older adults may be unable to walk to the bus stop, climb the stairs to a van, go to activities or pay for the transportation services. The financial problem is especially true for low-income older adults with limited financial resources. Particularly in crowded interchanges such as main train stations and central bus stations the older people find hard to organize travel. Lack of energy, confidence and anxiety about potential discomfort will exacerbate the impact of multiple minor disabilities. A typical trip using public transport will involve walking from home to the bus stop or station, identifying which service to take, boarding the bus or train, finding a seat, deciding where to alight, coping with interchanges as necessary and completing the journey to the final destination. For such a trip to be feasible the traveller must be confident that all the links in the chain will be manageable. The journey must be comprised of links that are accessible, coherent, compatible and continuous.

Melbourne, there is a long tradition of research into transport planning for aged people. This research provided information that until the early 1950s a majority of intra-urban travel was done by train, tram or bus [17]. But after the Suburban development outwardly radiating train and tram lines but this began to change. This leads a rise of car ownership levels in late 1950s [18]. As this continued through the 1960s and 1970s house building occurred further away from the fixed tram and train routes. With the development of Melbourne the extension of tram \& train network was minimal [19]. Travel within and between the newly built housing areas required a car because tram and train services were beyond walking distance plus the low population densities made bus services uneconomical. In turn, the journey to work length for many Melburnians increased [20] as did the trip to other amenities including shops, health and welfare services. Social security is another obligation to use public transport for elderly specially women. This tends to favour car use. Poorly maintained bus stops (specially in winter) \& not having accessible zebra crossing (in particularly for low vision people) [21] are another reason to avoid public transport for senior commuters. Table 2 represents the summary or average trip time comparison among different transport mode for elderly around greater Melbourne.

Table 2. Average trip time for elderly in Melbourne (VISTA 2012 [16]).

\begin{tabular}{|c|c|c|c|}
\hline & \multicolumn{3}{|c|}{ Home sub Region } \\
\hline $\begin{array}{c}\text { Transport } \\
\text { System }\end{array}$ & $\begin{array}{c}\text { Melbourne } \\
\text {-Inner, } \\
\text { Mins }\end{array}$ & $\begin{array}{c}\text { Melbourne- } \\
\text { Middle, } \\
\text { Mins }\end{array}$ & $\begin{array}{c}\text { Melbourn } \\
\text { e-Outer, } \\
\text { Mins }\end{array}$ \\
\hline $\begin{array}{c}\text { Public } \\
\text { Transport }\end{array}$ & 44 & 71 & 66 \\
\hline $\begin{array}{c}\text { Active } \\
\text { Transport }\end{array}$ & 16 & 14 & 13 \\
\hline $\begin{array}{c}\text { Private } \\
\text { Vehicle }\end{array}$ & 17 & 18 & 19 \\
\hline Other & 45 & 16 & 18 \\
\hline
\end{tabular}

\section{Applied strategies for aged friendly transport system}

Promote mobility and accessibility in the transport system is a key element for the population with the reduced mobility conditions. The promotion is already developed and introduced to the existing transport system [22]. To improve the transport system for elderly we need to think some basic criteria or services. [23] Provides a list of qualities for aged friendly transport system. A number of studies have been conducted to provide this key service to maintain good quality of transport system.

Furthermore some strategic proposal has been made to attract elderly to use public transport. The studied proposal as explained as follows:

- According to [6] more flexible smart ticketing for public transport is one of the strategies. More discounts on off-peak rail travel will attract senior travel as well as helps the commercial revenue of transport system. A mixture of buses, community transport, taxis and lift-giving with good publicity and reliable services, would increase mobility amongst older people (particularly in rural areas). Also providing more benches, more public toilets and better street lighting would make walking easier and more attractive for elderly.

- Another study focuses on free bus pass to most common travel places for passenger aged over 60 [24].

- Provide STS (special transport service) for the people are unable to use public transport or car. STS often provides through public procurement of taxi services [25].

- Older people housing option should be more flexible which leads them easy access to daily necessity. New housing rules should be made to motivate future agein-place situation. Older people need housing options which do not force them to depend on cars. This includes residential alternatives near secure shopping and medical choices to which they can walk or easily take public transit. New housing models are being developed. The elderly who choose 
to stay their own place can get home delivery services for everyday goods [26].

- Another study focused on public transport stops improvement. For passengers with reduced vision, tactile markers led the way to the doorway of the bus and bus shelter. This will provide more mental safety to elderly [21].

- School \& post office vehicles have limited use for a day. These can be used as a supportive vehicle for elderly. However unsuitability of insurance, administration, design, availability and routing arrangements can make difficulties to the contribution [15].

- In some countries a number of necessary improvements include space for a wheelchair with suitable safety provisions ( including raised kerbs), a boarding device to enable wheelchair users to get on and off vehicles, a minimum number of priority seats on buses for disabled passengers, specification of the size and height of steps, handrails to assist disabled people, colour contrasting of features such as handrails and steps to help partially sighted people, easy to use bell pushes throughout a bus, audible and visual signals to stop a bus or to request a boarding device and equipment to display the route and destination [27]. Similar regulations need to apply for new rail vehicles and trams [28]. These policies and practices are being beneficiary not only to elderly but for those with luggage or children.

- The London concessionary travel scheme, funded by London local authorities, allows free off-peak travel for elderly and disabled residents on buses, the Underground, Docklands Light Railway and London rail services [14]. This represents the most advantageous scheme, in terms of cost to users and geographical extent of travel.

\section{Proposed strategies}

It is always challenging to deal with elderly persons' transport. One of the principal reasons that elderly have travel problems are related to their lack of physical resilience, which maybe either large or small. An accessible and comprehensive public transport system can provide a low cost, low emission alternative to the car. It is therefore important to understand trends in public transport use among the elderly. It helps to understand the long-term impacts of an ageing population on the transport network. The study identifies strategies to increase public transport accessibility for senior commuters. Proposed strategies to increase elderly public transport accessibility are:

- Shuttle bus route service: Analysing the travel time \& destination a shuttle bus network will be introduced. From existing datasets mostly liveable elderly suburb, travel destination \& travel time can be identified. The new shuttle bus service network depends on these three main variables. The route network of the shuttle service can use as elderly special service. It can be also modified according to needs of the elderly travel pattern.
- Existing public transport time table modify: As elderly mostly avoid peak hour travel so the suburban public transport time table can be changed accordingly. Service frequency can be adjusted when they travel most. This will drive elderly travel mode towards public transport. Specially for suburban bus service it can be adjusted.

- Ride share apps: Elderly persons are more comfortable with personal vehicle; ride share can be effective for day to day need. Through any ride share service a number of passengers can travel towards similar destination without waiting for public transport.

\section{Conclusions}

With active aging comes the ability and desire to remain living in one's own home and community safely, independently and comfortably for a longer period of time after retirement [16]. As people increasingly retire in the same neighbourhood where they lived most of their adult working life the growth of older adults is particularly rapid in the suburbs of metropolitan areas [29]. For the past two decades, this broader definition of 'ageing in place' has been adopted by researchers and policymakers to describe a number of seniors prefer to live. Research conducted in Australia and elsewhere in the world has consistently shown that most seniors prefer to live as long as possible in their homes [30]. This desire to 'age in their own place' long and active involvement seniors have had with the family home, their neighbours plus the surrounding local community. The option of moving into a retirement village is unattractive due to their high entry cost and ongoing charges. The nursing homes have low patient to staff ratios. Furthermore regular media reports are published of elderly patients being neglected. Hence living in own home provide flexibility \& independence. If the public transport is easily accessible to elderly active aging can establish. Proposed strategies are straight forward to apply.

\section{References}

1. B. Aguiar, B \& R. Macário, 'The need for an Elderly centred mobility policy', Transportation Research Procedia, 25, 4355-4369 (2017)

2. S. Rosenbloom \& J. Morris, 'Travel patterns of older Australians in an international context: Policy implications and options', Transportation Research Record, 1617, 189-193 (1998)

3. Australian Bureau of Statistic, Population projections: a tool for examining population ageing,. Green, Robin, ed. Year book Australia 2008. Belconnen, ACT: Australian Bureau of Statistics, 2008 (Year book no.90), pp.188-191, ISSN: 0312-4746 (2008)

4. S. Kim \& G.F. Ulfarsson, Travel mode choice of the elderly: Effects of personal, household, neighborhood, and trip characteristics, Transportation Research Record, 1894, 117-126 (2004)

5. R. Alsnih \& DA. Hensher, 'The mobility and accessibility expectations of seniors in an aging 
population', Transportation Research Part A: Policy and Practice, 37, 10, 903-916 (2003)

6. R. Mackett, 'Improving accessibility for older peopleInvesting in a valuable asset', Journal of Transport \& Health, 2, 1, 5-13 (2015)

7. B. Engels \& G-J. Liu, 'Ageing in Place: The Out-ofHome Travel Patterns of Seniors in Victoria and its Policy Implications', Urban Policy and Research, 31, 2, 168-189 (2013)

8. JA. Davey, 'Older people and transport: coping without a car', Ageing and Society, 27, 1, 49-65 (2007)

9. S. Rosenbloom \& J. Morris, 'Travel patterns of older Australians in an international context: Policy implications and options', Transportation Research Record, 1617, 189-193 (1998)

10. C. O'Fallon and C. Sullivan, 'Older people's travel patterns and transport sustainability in New Zealand cities'.

http://www.pinnacleresearch.co.nz/research/older_people pdf

11. H. Li, R. Raeside, T. Chen \& RW. McQuaid, 'Population ageing, gender and the transportation system', Research in Transportation Economics, 34, 1, 3947(2012)

12. S. Fobker \& R. Grotz, 'Everyday Mobility of Elderly People in Different Urban Settings: The Example of the City of Bonn, Germany', Urban Studies, 43, 1, 99-118 (2006)

13. D. Pramitasari \& A. Sarwadi, 'A Study on Elderly's Going Out Activities and Environment Facilities', Procedia Environmental Sciences, 28, 315-323(2015)

14. D. Metz, 'Transport policy for an ageing population', Transport Reviews, 23, 4, 375-386(2003)

15. N. Ashford \& WG. Bell, 'Transport for the elderly and the handicapped-an overview from the late 70', Transportation Planning and Technology, 5, 2, 71-78 (1979)

16.Victorian Integrated Survey of Travel and Activity (VISTA).

https://transport.vic.gov.au/data-and-research/vista

17. B. Engels \& G-J. Liu, 'Ageing in Place: The Out-of-

Home Travel Patterns of Seniors in Victoria and its Policy Implications', Urban Policy and Research, 31, 2, 168-189 (2013)

18. G. Davison, S. Yelland \& A. Davison, A, Car wars: how the car won our hearts and conquered our cities, Journal of Australian studies, 83, 152-153, (2004)

19. P. Mess, A very public solution: Transport in the dispersed city, [Book Review], Melbourne University Press, (ISBN) 0522848672 :(ISBN) 0522848672
20. KEN. Johnson, \& J. Black, 'An aid to understanding car ownership a study of households in four melbourne suburbs', International Journal of Transport Economics / Rivista internazionale di economia dei trasporti, vol. 4, 2, 147-167(1977)

21. J. Aarhaug \& B. Elvebakk, 'The impact of Universally accessible public transport-a before and after study', Transport Policy, 44, 143-150 (2015)

22. X. Karekla, T. Fujiyama \& N. Tyler 'Evaluating accessibility enhancements to public transport including indirect as well as direct benefits', Research in Transportation Business \& Management, 2, 92-100 (2011) 23. R. Johnson, J. Shaw, J. Berding, M. Gather \& M. Rebstock, 'European national government approaches to older people's transport system needs', Transport Policy, 59, 17-27 (2017)

24. J. Barnes, A. Morris, R. Welsh, R, S. Summerskill, R. Marshall, D. Kendrick, P. Logan, A. Drummond, S. Conroy, B. Fildes \& J. Bell, Injuries to older users of buses in the $U K$ ', Planning and Operations, 8, 1, 25-38 (2016)

25. L. Hansson, \& J. Holmgren, 'Reducing dependency on special transport services through public transport', Transportation Research Procedia, 25, 2450-2460 (2017) 26. S. Rosenbloom, 'Sustainability and automobility among the elderly: An international assessment', Planning - Policy - Research - Practice, 28, no. 4, 375408 (2001)

27. S. Sharp \& D. Macdonald, 'Regulating for Improved Accessibility to Buses', Towards Safety, Independence and Security. 9th International Conference on Mobility and Transport for Elderly and Disabled People, Warsaw , Poland (2001)

28. M. Deieammes \& A. Frye, 'Accessible Railways in Europe: recommendations from the COST335 European research action', 1, 68-74 (2001)

29. EE. Boschmann \& SA. Brady, 'Travel behaviors, sustainable mobility, and transit-oriented developments: a travel counts analysis of older adults in the Denver, Colorado metropolitan area', Journal of Transport Geography, 33, 1-11 (2013)

30. D. Olsberg \& M. Winters, Ageing in place: intergenerational and intrafamilial housing transfers and shifts in later life, AHURI Final Report No. 88, Australian Housing and Urban Research Institute Limited,Melbourne,https://www.ahuri.edu.au/research/fin al-reports/88 (2005). 